\title{
Stabilization of Metal Ensembles at Room Temperature: Palladium Clusters in Zeolltes
}

\author{
Karin Moller, ${ }^{\dagger}$ Diek C. Koningsberger, ${ }^{\ddagger}$ and Thomas Bein ${ }^{*}{ }^{\dagger}$ \\ Department of Chemistry, University of New Mexico, Albuquerque, New Mexico 87131, and Laboratory for \\ Inorganic Chemistry and Catalysis, Eindhoven University of Technology, $5600 \mathrm{MB}$ Eindhoven, \\ The Netherlands (Received: November 2, 1988; In Final Form: April 10, 1989)
}

\begin{abstract}
Palladium clusters of low nuclearity have been prepared in the cavities of $\mathrm{X}$ zeolites via ion exchange with $\mathrm{Pd}\left(\mathrm{NH}_{3}\right)_{4} \mathrm{Cl}_{2}$ oxidative dehydration, and subsequent reduction of the dry Pd(II) zeolites with hydrogen at 295 and $425 \mathrm{~K}$. Detailed EXAFS analysis of Pd K-edge data shows that the average first-shell Pd-Pd coordination number of the reduced system is only about $N=1.5$ at a distance of $2.78 \AA$. A long, relatively disordered coordination of the reduced Pd to framework oxygen and silicon indicates the stabilizing, templating function of the zeolite matrix. Geometric models based upon the EXAFS results show that intrazeolite $\mathrm{Pd}_{2}, \mathrm{Pd}_{3}$, and $\mathrm{Pd}_{4}$ clusters are formed by partial occupation of $\mathrm{SI}^{\prime}$ and $\mathrm{SII}^{\prime}$ positions of the sodalite subunits of the zeolite. This study presents evidence for the formation of "molecular" metal ensembles stabilized in an open-framework matrix to at least $425 \mathrm{~K}$.
\end{abstract}

\section{Introduction}

Small metal particles or clusters have attracted great interest during the past decade. Optical, electronic, and catalytic characteristics of clusters are expected to change from "bulk" properties to "molecular" properties within a certain size range. ${ }^{1,2}$ With regard to electronic properties, this change is represented by the transition of the electronic band structure of a crystal to the molecular orbital levels of species a few atoms in size. A heterogeneous catalytic reaction at a metal surface is affected not only by the electronic properties of the metal but also by the structure of coordination sites. ${ }^{3}$ Since the cluster size determines the relative population of coordination $\operatorname{sites}^{4}$ and possibly its molecular symmetry, it was suggested to be responsible for modified selectivities in a number of catalytic reactions. Controlled synthesis and examination of clusters in the intermediate size range is of particular interest, because this would potentially allow fine-tuning of the properties of electronic materials and catalyst systems.

Simple structures such as dimers and trimers of most alkalimetal and transition-metal elements have been studied in cold $\mathrm{He}$ or Ar matrices utilizing a wide array of methods like UV, ${ }^{5,6}$ IR, ${ }^{7}$ Raman, Mössbauer, ${ }^{8}$ ESR, ${ }^{9}$ and EXAFS. ${ }^{10}$ On the basis of spectroscopic evidence, linear, bent, or triangular structures or even fluctuations between equivalent configurations were suggested for trimers of different elements. ${ }^{11,12}$ Molecular beam experiments were used to study unperturbed particles with two to several tens of atoms. ${ }^{13}$ However, studies of the effect of cluster size and morphology on physical and chemical properties have typically been limited to these extreme conditions because it appears to be very difficult to form bare molecular metal clusters (e.g., 2-10 atoms) that are stable under ambient conditions.

The present study is aimed at the controlled synthesis of molecular, well-defined palladium clusters that are stabilized in an open-framework matrix. Numerous groups have synthesized small transition-metal particles by impregnation or ion exchange onto a variety of supports, followed by reduction. Typically, a distribution of particle sizes results, raising problems with characterization and with the correlation of catalytic behavior to particle shapes and properties. An alternative strategy based on "heterogenizing" well-defined molecular clusters on a support can suffer from problems such as high mobility and agglomeration of the molecular precursors upon removal of remaining ligands. ${ }^{14,15}$

Based upon their unique, cyrstalline pore structure with dimensions at the molecular level (pore sizes between 3 and $12 \AA$ are common) molecular sieves appear to be the most promising supports for the room-temperature stabilization of small metal clusters. Zeolite $X$ and $Y$, with cages $12 \AA$ in size, have suc-

\footnotetext{
* To whom correspondence should be addressed

${ }^{\dagger}$ University of New Mexico.

${ }^{t}$ Eindhoven University of Technology.
}

cessfully been used to restrict metal agglomeration to the dimensions of their internal pores (a $10-\AA \mathrm{Pt}$ particle corresponds to ca. 40 atoms). Smaller, zeolite-stabilized clusters have only been detected as charged species such as $\mathrm{Na}_{4}{ }^{3+16}$ or $\mathrm{Ag}_{3}{ }^{2+17}$. The particle size of $\mathrm{Pd}$ and $\mathrm{Pt}$ phases encapsulated in zeolite hosts can be controlled by choosing appropriate reduction conditions for the ion-exchanged, dehydrated precursor form. ${ }^{18-20}$ On the basis of $\mathrm{X}$-ray diffraction studies, a bidisperse distribution of $\mathrm{Pd}$ particles appears to be typical: In addition to particles $10-20 \AA$ in size, a second $\mathrm{Pd}$ phase was assigned to $\mathrm{Pd}$ atoms in the cage systems. ${ }^{21,22}$

We wish to report the synthesis and characterization of $P d$ ensembles, consisting of two to four correlated atoms, which are stabilized at room temperature in an open, chemically accessible zeolite matrix. These ensembles are ideal model systems to study physical, chemical, and catalytic characteristics of small metal systems at ambient conditions. Characterization of the clusters was done by means of X-ray absorption spectroscopy (EX-

(1) Contribution of Clusters Physics to Materials Science and Technology; Davenas, J., Rabette, P. M., Eds.; NATO ASI Series E104; Martinus Nijhoff: Dordrecht, 1986.

(2) Metal Clusters; Moskovits, M., Ed.; Wiley: New York, 1986

(3) Somorjai, G. A. In Catalyst Design; Hegedus, L. L., Ed.; Wiley: New York, 1987; p 11 .

(4) Van Hardeveld, R.; Hartog, F. Surf. Sci. 1969, 15, 189.

(5) DeVore, T. C.; Ewing, A.; Franzen, H. F.; Calder, V. Chem. Phys. Lett. $1975,35,78$.

(6) Jansson, K.; Scullman, R. J. Mol. Spectrosc. 1976, 6l, 299.

(7) Hulse, J. E.; Moskovits, M. Surf. Sci. 1976, 57, 125

(8) Dyson, W.; Montano, P. A. J. Am. Chem. Soc. 1978, 100, 7439. 6226 .

.

(10) Montano, P. A.; Schulze, W.; Tesche, B.; Shenoy, G. K.; Morrison, T. I. Phys. Rev. B 1984, 30,672.

(11) Moskovits, M.; DiLella, D. P. J. Chem. Phys. 1980, 72, 2267.

(12) Baetzold, R. C. In Metal Clusters; Moskovits, M., Ed.; Wiley: New York, $1986 ;$ p 5

(13) Gole, J. L. In Metal Clusters; Moskovits, M., Ed.; Wiley: New York, $1986 ;$ p 131

(14) Metal Clusters in Catalysis; Gates, B. C., Guczi, L., Knozinger, H., Eds.; Elsevier: Amsterdam, 1986

(15) Catalysis by Supported Complexes; Yermakov, Y. I., Kuznetsov, B. N., Zakharov, V. A., Eds.; Elsevier: Amsterdam, 1981 .

(16) (a) Harrison, M. R.; Edwards, P. P.; Klinowski, J.; Thomas, J. M.; Johnson, D. C.; Page, C. J. J. Solid State Chem. 1984, 54, 330. (b) Martens, L. R. M.; Grobet, P. J.; Jacobs, P. A. Nature 1985, 315, 568.

(17) (a) Gellens, L. R.; Mortier, W. J.; Schoonheydt, R. A.; Uytterhoeven, J. B. J. Phys. Chem. 1981, 85, 2783. (b) Gellens, L. R.; Mortier, W. J.; Uytterhoeven; J. B. Zeolites 1981, $l, 11$.

(18) Exner, D.; Jaeger, N.; Moller, K.; Schuiz-Ekloff, G. J. Chem. Soc., Faraday Trans. 1 1982, 78,3537

(19) Exner, D.; Jaeger, N.; Moller, K.; Nowak, R.; Schrubbers, H. Schulz-Ekloff, G.; Ryder, P. Studies in Surface Science and Catalysis; Jacobs, P. A., Ed.; Elsevier: Amsterdam, 1982; Vol. 12, p 205.

(20) Bergeret, G.; Gallezot, P.; Imelik, B. J. Phys. Chem. 1981, 85, 411.

(21) Gallezot, P.; Imelik, B. Adv. Chem. Ser. 1973, 121, 66.

(22) Bergeret, G.; Tran Manh Tri; Gallezot, P. J. Phys. Chem. 1983, 87 , 

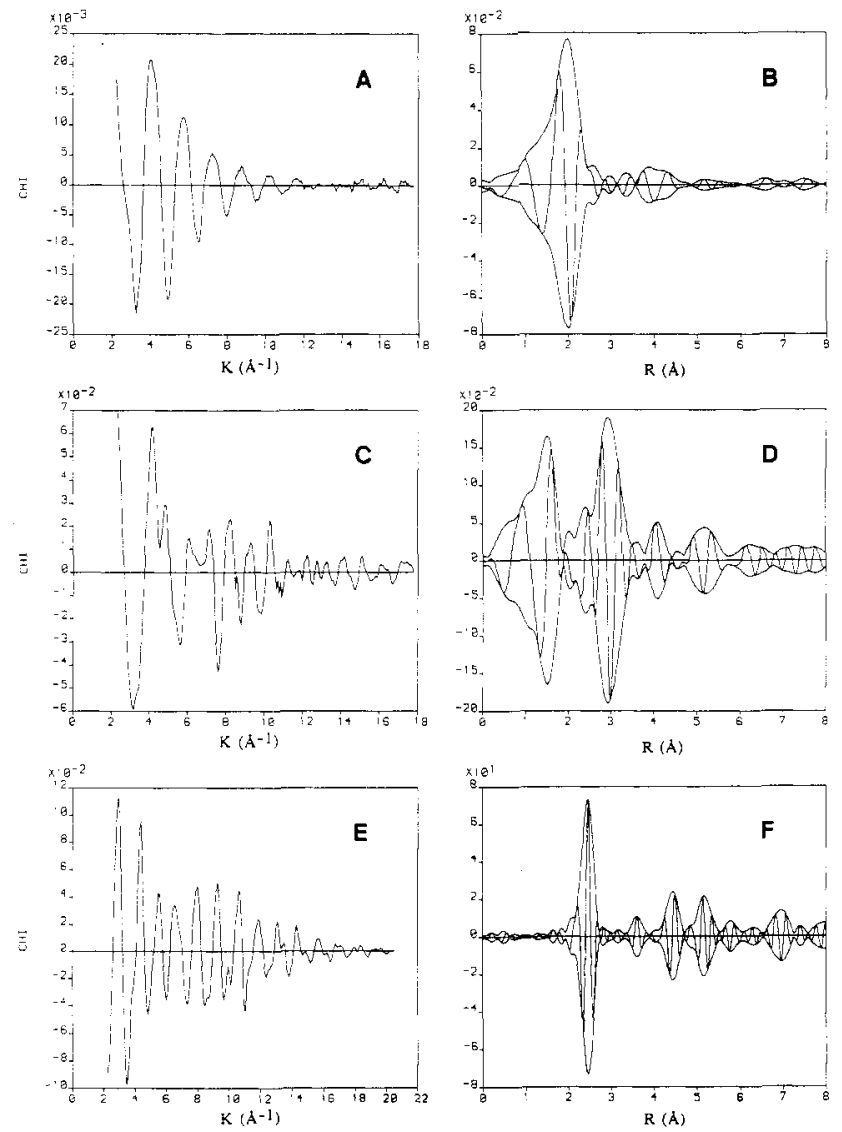

Figure 1. A, C, E, Pd K-edge normalized EXAFS data; B, D, F, Fourier transformations of reference compounds. (A, B) CdS; (C, D) PdO; (E, F) Pd foil.

AFS). 23,24 A detailed data analysis, utilizing phase- and amplitude-corrected Fourier transformations (FT) of the EXAFS data combined with a difference-file and iterative fitting technique provided insight in the structure and local environment of these clusters.

\section{Experimental Procedures}

Zeolite X (Alfa No. 020684) was ion-exchanged with stoichiometric amounts of $\mathrm{Pd}\left(\mathrm{NH}_{3}\right)_{4} \mathrm{Cl}_{2}$ and washed until chlorine free. The sample was heated in a shallow bed under a stream of oxygen up to $625 \mathrm{~K}$, with a heating rate of $1 \mathrm{~K} / \mathrm{min}$. It should be noted that heating the Pd-exchanged zeolite under vacuum as opposed to oxygen causes an autoreduction process that forms large metal clusters (50-100 $\AA$ ) under decomposition of the ammine ligands. ${ }^{25}$ Oxygen atmosphere prevents this autoreduction. After evacuation at $10^{-5}$ Torr, a fraction of the samples was exposed to dry hydrogen, either at 600 Torr for $1 \mathrm{~h}$ at room temperature or under a stream of hydrogen at $425 \mathrm{~K}$ overnight. The samples were evacuated at the reduction temperature for $15 \mathrm{~min}$. The unit cell composition was determined by chemical analysis (Galbraith Laboratories) to be $\mathrm{Pd}_{20.5} \mathrm{Na}_{46}\left(\mathrm{AlO}_{2}\right)_{87}\left(\mathrm{SiO}_{2}\right)_{105}$. The samples were embedded in pellet form in an octadecane, eicosane 1:1 mixture and stored under nitrogen atmosphere in a glovebox until EXAFS data were taken. This technique has been shown to exclude contamination with air. ${ }^{26}$

EXAFS measurements were done at the X-11A beam line at NSLS, Brookhaven, Long Island, with an electron energy of 2.5 $\mathrm{GeV}$ and ring currents between 40 and $120 \mathrm{~mA}$. Data were

(23) Teo, B. K. EXAFS: Basic Principles and Data Analysis; Springer: Berlin, 1986 .

(24) X-Ray Absorption: Principles, Applications, Techniques of EXAFS $S E X A F S$ and $X A N E S$; Koningsberger, D. C., Prins, R., Eds.; Wiley: New York, 1988.

(25) Moller, K.; Bein, T. J. Phys. 1986, C8, 231.

(26) Bein, T.; McLain, S. J.; Corbin, D. R.; Farlee, R. D.; Moller, K.; Stucky, G. D.; Woolery, G.; Sayers, D. J. Am. Chem. Soc. 1988, 110, 1801
TABLE I: Fourier Transformation Ranges and Crystallographic Data of Reference Compounds

\begin{tabular}{llllll}
\hline $\begin{array}{c}\text { ref } \\
\text { compd }\end{array}$ & $k^{n}$ & $\Delta k / \AA^{-1}$ & \multicolumn{1}{c}{$\Delta R / \AA$} & $R / \AA$ & $N$ \\
\hline Pd foil & $k^{3}$ & $2.3-20.0$ & $1.7-2.6$ & 2.744 & 12 \\
PdO & $k^{1}$ & $2.6-11.0$ & $0.2-1.9$ & 2.017 & 4 \\
CdS & $k^{1}$ & $2.6-11.0$ & $0.7-2.6$ & 2.52 & 4
\end{tabular}
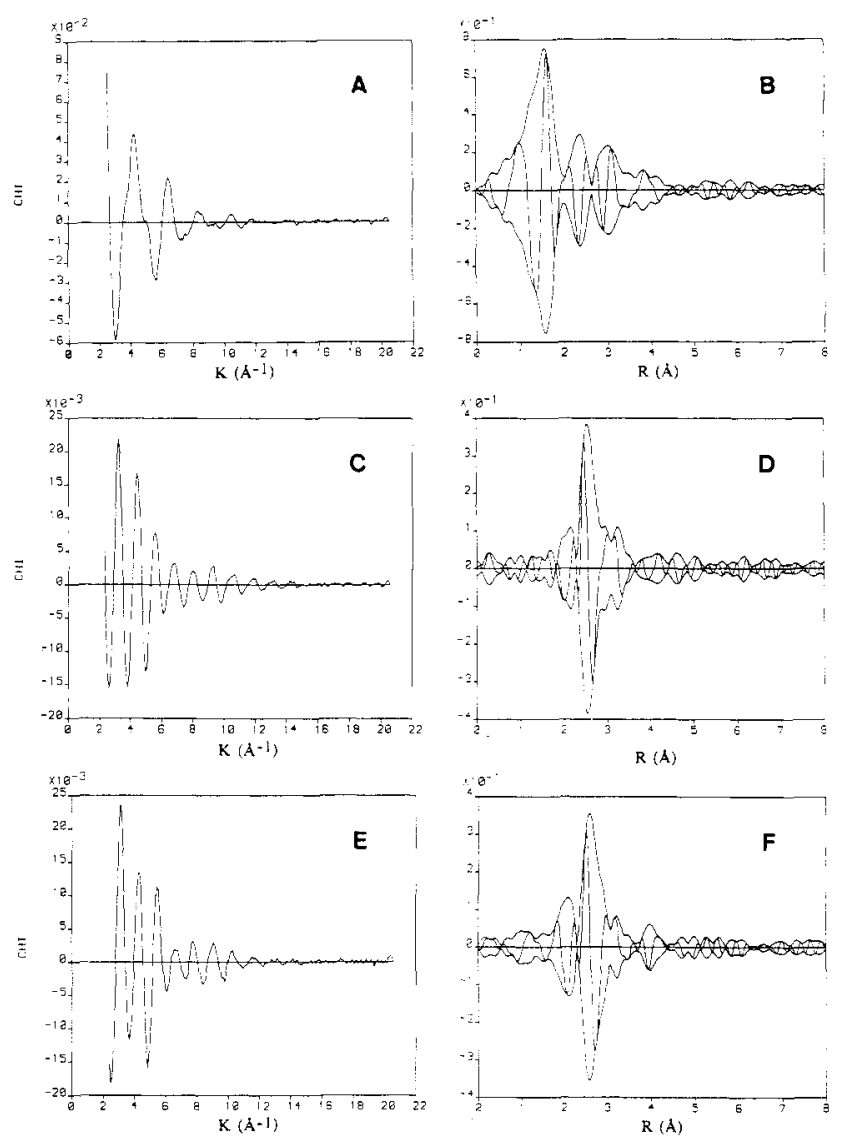

Figure 2. A, C, E, Pd K-edge normalized EXAFS data; B, D, F, their Fourier transformations over a range of $k=2.7-17 \AA^{-1}$, using a $k^{2}$ weighting function. (A, B) Sample PdXO; (C, D) sample PdX; (E, F) sample PdX2.

collected with a $\mathrm{Si}(400)$ crystal pair monochromator at the Pd $\mathrm{K}$ edge $(24350 \mathrm{eV})$ at ca. $100 \mathrm{~K}$. A $0.025-\mathrm{mm} \mathrm{Pd}$ foil, PdO, and CdS powder served as reference structures for the EXAFS analysis. Geometric model calculations were carried out with the Chem3D program (CSC, Cambridge) for different zeolitic $\mathrm{Pd}(0)$ positions, based on crystallographic data for faujasite ${ }^{27}$ and on coordination distances from the EXAFS analysis.

\section{Experimental Results and Data Analysis}

Normalized EXAFS data after standard background substraction $^{28}$ and Fourier transformations of reference compounds which were used for the fit procedure are shown in Figure 1. All peak positions are shifted to lower bond distances due to phase-shift effects and will be referred to as uncorrected values. Cadmium sulfide (Figure 1A,B) was used as a reference for the $\mathrm{Pd}-\mathrm{Si} / \mathrm{Al}$ scatter pair since a suitable $\mathrm{Pd}-\mathrm{Si}$ compound is not available. Transferability of the backscattering amplitude and phase function of CdS can be assumed. when a deviation of bond distances $\Delta R$ $<0.04 \AA$ and of the coordination number $\Delta N<30 \%$ is accepted. ${ }^{29}$ Isolation of phase and amplitude functions was performed with parameters listed in Table I.

Experimental EXAFS data and Fourier transformations of PdX zeolite samples after three different treatments are shown in Figure

(27) Bauer, W. H. Am. Mineral. 1964, 49, 697.

(28) Cook, J. W.; Sayers, D. E. J. Appl. Phys. 1981, 52, 5024.

(29) Lengeler, B. J. Phys. 1986, C8, 75. 
TABLE II: Fit Results Obtained from EXAFS Analysis

\begin{tabular}{|c|c|c|c|c|c|}
\hline $\begin{array}{l}\text { atom } \\
\text { pair }\end{array}$ & $N_{\text {EXAFS }}$ & $N$ & $R / \AA$ & $\Delta \sigma^{2} / \AA^{2}$ & $\Delta E / \mathrm{eV}$ \\
\hline \multicolumn{6}{|c|}{$\operatorname{PdX}$} \\
\hline $\mathrm{Pd}-\mathrm{Pd}$ & 1.5 & & 2.78 & 0.0047 & -8.8 \\
\hline $\mathrm{Pd}-\mathrm{O}$ & 2.1 & 2.7 & 2.76 & 0.0130 & 4.2 \\
\hline $\mathrm{Pd}-\mathrm{Si}$ & 4.4 & 6.0 & 3.44 & 0.0210 & -15.0 \\
\hline \multicolumn{6}{|c|}{$\mathrm{PdX} 2$} \\
\hline $\mathrm{Pd}-\mathrm{Pd}$ & 1.9 & & 2.79 & 0.005 & 0.0 \\
\hline $\mathrm{Pd}-\mathrm{O}$ & 1.3 & & 2.28 & 0.009 & 5.1 \\
\hline $\mathrm{Pd}-\mathrm{O}$ & 1.5 & 2.0 & 2.80 & 0.015 & -1.7 \\
\hline $\mathrm{Pd}-\mathrm{Si}$ & 3.3 & 4.5 & 3.44 & 0.015 & -16.0 \\
\hline
\end{tabular}

2: after oxygen pretreatment at $625 \mathrm{~K}(\mathrm{PdXO}$, Figure 2A,B); after $\mathrm{H}_{2}$ exposure at room temperature ( $\mathrm{PdX}$, Figure $\left.2 \mathrm{C}, \mathrm{D}\right)$; and after hydrogen reduction at $425 \mathrm{~K}$ (PdX2, Figure 2E,F). All Fourier transformations are weighted with the same factor and can directly be compared with respect to peak magnitudes. In sample $\mathrm{PdXO}$, the coordination of $\mathrm{Pd}^{2+}$ to oxygen with a $\mathrm{Pd}-\mathrm{O}$ distance of $2.07 \AA$ ( $1.5 \AA$ uncorrected) is detected as the main peak (Figure 2B). ${ }^{25}$ This corresponds exactly to results from X-ray diffraction studies of similar palladium exchanged zeolites. Twelve of $13.7 \mathrm{Pd}$ atoms exchanged into the zeolite were detected in $\mathrm{SI}^{\prime}$ positions (see Figure 5A) with a bond distance of $2.07 \AA$ to three oxygens of the zeolite hexagonal windows. ${ }^{20}$ The coordination of Pd to the zeolite is indicated in the EXAFS spectrum by the concomitant appearance of a peak at about $3.0 \AA$ (uncorrected), typical for $\mathrm{Si} / \mathrm{Al}$ scatterer of the zeolite framework. An intermediate peak indicates the onset of palladium reduction by decomposition of the ammine ligands.

If the sample $\mathrm{PdXO}$ is exposed to hydrogen at $295 \mathrm{~K}(\mathrm{PdX})$ and $425 \mathrm{~K}(\mathrm{PdX} 2)$, drastic changes are visible in the corresponding EXAFS data (Figure 2D,F). The unsmoothed, low-noise data do not show any sign of remaining cationic $\mathrm{Pd}$-zeolite-oxygen coordination between 1 and $2 \AA$, the range of the $\mathrm{Pd}-\mathrm{O}$ contribution in sample $\mathrm{PdXO}$. Instead, a very small, well-resolved contribution from Pd-Pd scattering is present. No outer palladium shells are visible, indicating an extremely small cluster size.

Since both hydrogen-treated samples show very similar EXAFS data, we will limit a detailed discussion to sample PDX. The fit results for both samples are listed in Table II. A Pd-Pd phaseand amplitude-corrected Fourier transformation of a single-shell pure Pd backscatterer should show only a single peak at the correct position for this bond distance and small symmetric side lobes. ${ }^{30}$ Such a transformation was performed on sample $\mathrm{PdX}$ and $\mathrm{PdX} 2$, and the imaginary parts of the Fourier transformations are shown in Figure 4B,D (solid lines). We note that an asymmetry exists on both sides of the main peaks indicating other contributions in addition to $\mathrm{Pd}$. We used the difference-file technique to deconvolute these contributions as described below.

The amplitude function of heavy elements extends further into energy space than that of light elements and is predominant in the range $k=7-16 \AA^{-1}$. If EXAFS data are weighted by a higher order of $k$ and then Fourier transformed in this data range, light elements are effectively discriminated. Figure $3 \mathrm{~A}$ shows sample PdX after a transformation at $k=7-14 \AA^{-1}$, resulting in symmetric side lobes after phase and amplitude correction for $\mathrm{Pd}$ metal. The positive peaking of the imaginary part at a distance typical for the first $\mathrm{Pd}-\mathrm{Pd}$ shell identifies this contribution to be due to Pd backscattering. An inverse Fourier transformation of this shell was performed between 2.4 and $3.2 \AA$, and the resulting $\chi$-function was fitted with the Pd foil reference in an iterative approach. Initial fitting with $P d$ foil resulted in a coordination number smaller than 2.0 and $R=2.76 \AA$. To obtain more accurate values, a new reference file with similar parameters was calculated from Pd foil data, Fourier transformed, and Fourier filtered over the same data range as the unknown. The excellent fit for this part is compared to the original data and shown in Figure $3 \mathrm{~B}$. No difference between the experimental data and the

(30) Van Zon, J. B. A. D.; Koningsberger, D. C.; van't Blik, H. F. J.; Sayers, D. E. J. Chem. Phys. 1985, 82, 5742.
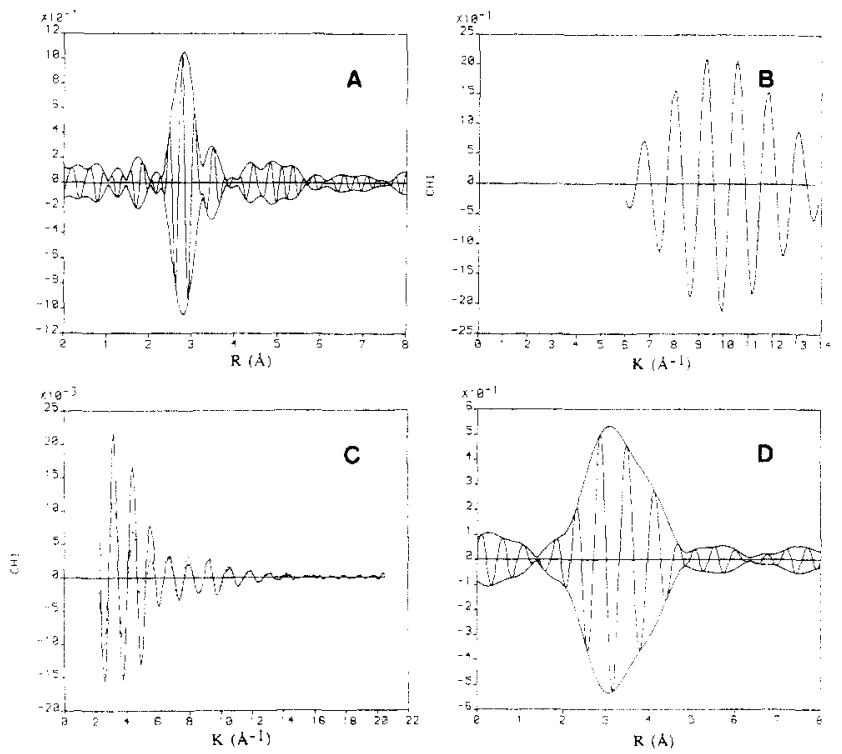

Figure 3. EXAFS data of sample PdX. (A) Magnitude and imaginary part of the $k^{2}$ weighted Fourier transformation between 7 and $14 \AA^{-1}$, phase and amplitude corrected with Pd foil. (B) Inverse $k^{2}$ Fourier transformation on (A) between 2.4 and $3.2 \AA$, original data (-) and fit (...). (C) Original $\chi$ data ( $(-)$ and calculated Pd-Pd contribution (...). (D) Difference file between original data and calculated $\mathrm{Pd}-\mathrm{Pd}$ contribution, $k^{2}$ Fourier transformed between 3.5 and $7.5 \AA^{-1}$, phase corrected with $\mathrm{PdO}$.

fit is visible. The obtained fit values were further used to calculate the Pd-Pd contribution for the whole data range (see Figure $3 \mathrm{C}$ ). The value for the inner potential is expected to change in the final fit over the whole data set. The original data file and the calculated metal contribution compare well in the range $k>8 \AA^{-1}$, the region dominated by heavier elements. Differences between fit and experimental data in the lower $k$ range have to be attributed to light elements, which were analyzed subsequently. For this purpose, the calculated palladium contribution was subtracted from the raw data file.

The remaining difference file, phase corrected for a $\mathrm{Pd}-\mathrm{O}$ atom pair, was transformed into real space (Figure 3D). More than one distinct peak is visible in the imaginary part, suggesting the presence of a third scatterer in addition to oxygen. A similar procedure performed with $\mathrm{CdS}$ as reference for $\mathrm{Si}$ atoms showed a pronounced peak at a distance plausible for $\mathrm{Si}$. Since the zeolite matrix consists of oxygen and $\mathrm{Si} / \mathrm{Al}$ atoms, both should be detected as first and second neighbor shells for small metal clusters in close interaction with the zeolite. A two-shell fit of the difference file gave initial structural parameters for both backscattering contributions.

Using the parameters obtained from the difference file procedure, a three-shell fit was performed with the original data over a range $k=3.5-10.5 \AA^{-1}$. The final refinement resulted in coordination parameters for the three contributions as listed in Table II. The coordination numbers $N_{\text {EXAFS }}$ for the oxygen and $\mathrm{Si} / \mathrm{Al}$ neighbors were corrected for the difference in the electron mean free path $\lambda$ between references and analyzed samples: $N_{\text {EXAFS }}=N \exp \left[-2\left(R_{\text {EXAFS }}-R_{\text {REF }}\right) / \lambda\right]$ with $\lambda=6 \AA$. This is necessary to avoid too low coordination numbers since the bond distances of reference and sample differ by more than $0.5 \AA$. In Figure 4A,C the three EXAFS functions for the oxygen, silicon, and palladium scatterers are compared to the EXAFS of sample $\mathrm{PdX}$ and $\mathrm{PdX}$, all Fourier transformed under identical conditions. This comparison shows how the individual scatterers contribute to the total radial distribution function. The quality of the final fits is best compared by superimposing the imaginary parts of fit and experimental data as shown in Figure 4B,D.

\section{Discussion}

EXAFS spectroscopy is, unlike X-ray diffraction, capable of detecting the local coordination environment of an absorber atom 

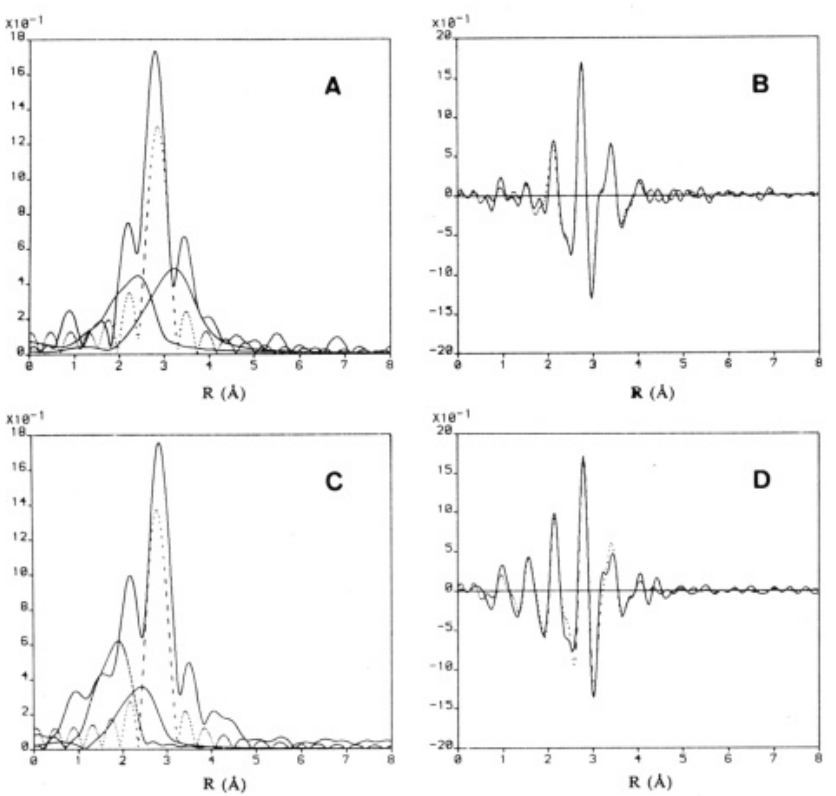

Figure 4. Three-shell-fitted EXAFS data of samples PdX and PdX2. A, $\mathrm{C}$, magnitudes, and $\mathrm{B}, \mathrm{D}$, imaginary parts of $k^{2}$ Fourier transformations $\left(k=3.6-10.7 \AA^{-1}\right)$, phase and amplitude corrected with Pd foil. (A) Original data of PdX (solid line) and calculated contributions for Pd-Pd (-.-), Pd-O (..., peaking at ca. $2.4 \AA)$, and $\mathrm{Pd}-\mathrm{Si}(\cdots$, peaking at ca. 3.2 $\AA$ ). (B) Original data (solid line) and final fit (...) of PdX. (C) Original data of PdX2 (solid line) and calculated contributions for Pd-Pd (--) and the two different $\mathrm{Pd}-\mathrm{O}$ distances (..., peaking at ca. 2 and $2.5 \AA$ ). (D) Original data (solid line) and final fit (...) of PdX2.

type even if this atom is randomly distributed throughout a sample. A detailed analysis allows detection of small contributions from coordination to an interface. The EXAFS data described above show that under carefully chosen conditions it is possible to achieve a total reduction of zeolite-supported palladium cations to metal clusters of molecular size at room temperature. This is concluded from the fact that no remaining ionic Pd-oxygen coordination at the original distance of $2.07 \AA$ (sample PdXO) is detected after reduction in sample PdX. Reduction of Pd-loaded zeolites Y with hydrogen between 300 and $475 \mathrm{~K}$ was reported to be incomplete. ${ }^{31}$ In our experiments with zeolite $\mathrm{Y}$ we obtained similar results at $300 \mathrm{~K} .{ }^{32}$ In contrast to zeolite $\mathrm{X}$, these samples were only fully reduced at $425 \mathrm{~K}$, giving rise to structural parameters very close to those described here.

The new, disordered $\mathrm{Pd}-\mathrm{O}$ coordination at $2.76 \AA$ in sample $\mathrm{PdX}$ is clearly not due to an ionic bond (e.g., $\mathrm{Pd}-\mathrm{O}$ in $\mathrm{PdO}=2.01$ $\AA$ ) but may be compared to the combined radii of $\mathrm{O}^{2-}=1.32 \AA$ and $\mathrm{Pd}^{0}=1.37 \AA$. We interpret this contribution as resulting from a weak interaction between the reduced metal atoms and the support which gives rise to an increased static disorder as indicated by the Debye-Waller factors for $\mathrm{Pd}-\mathrm{O}$ and $\mathrm{Pd}-\mathrm{Si}$ (Table II). Similar long metal-oxygen bond distances have been reported for a palladium phase in $\mathrm{Y}$ zeolites $\left(\mathrm{Pd}-\mathrm{O}=2.74 \AA\right.$ after $\mathrm{H}_{2}$ reduction at $420 \mathrm{~K}),{ }^{22}$ for silver clusters in zeolite $\mathrm{Y}(\mathrm{Ag}-\mathrm{O}=$ 2.67 and $2.79 \AA$ after $\mathrm{H}_{2}$ reduction at $348 \mathrm{~K}$ ), ${ }^{17}$ as well as between small supported $\mathrm{Rh}(0)$ clusters on $\mathrm{Al}_{2} \mathrm{O}_{3}$ or $\mathrm{TiO}_{2}{ }^{30,33}$ and interface oxygen. In their X-ray diffraction study of PdY zeolites, Bergeret et al. ${ }^{22}$ assigned the long bond distance of $2.74 \AA$ to palladium in $\mathrm{SI}^{\prime *}$ positions, which are slightly removed from $\mathrm{SI}^{\prime}$ along the $C_{3 v}$ axis (see below and Figure 5A). They interpreted their results with the presence of isolated Pd atoms because statistically only $1.3 \mathrm{Pd}$ atoms were present per sodalite cage.

As indicated in Table II, the average coordination number of $\mathrm{Pd}-\mathrm{Pd}$ in the zeolite samples discussed here is 1.5. This could point to the formation of dimeric and trimeric clusters. We find

(31) Vedrine, J. C.; Dufaux, M.; Naccache, C.; Imelik, B. J. Chem. Soc., Faraday Trans. I 1978, 74, 440.

(32) Moller, K.; Bein, T. Submitted for publication in J. Phys. Chem.

(33) Koningsberger, D. C.; Martens, J. H. A.; Prins, R.; Short, D. R.; Sayers, D. E. J. Phys. Chem. 1986, 90, 3047.

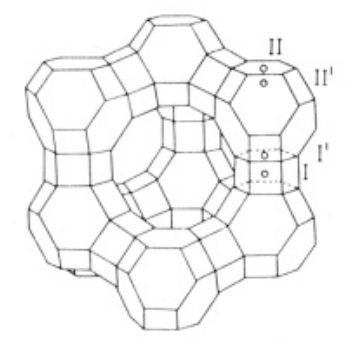

A
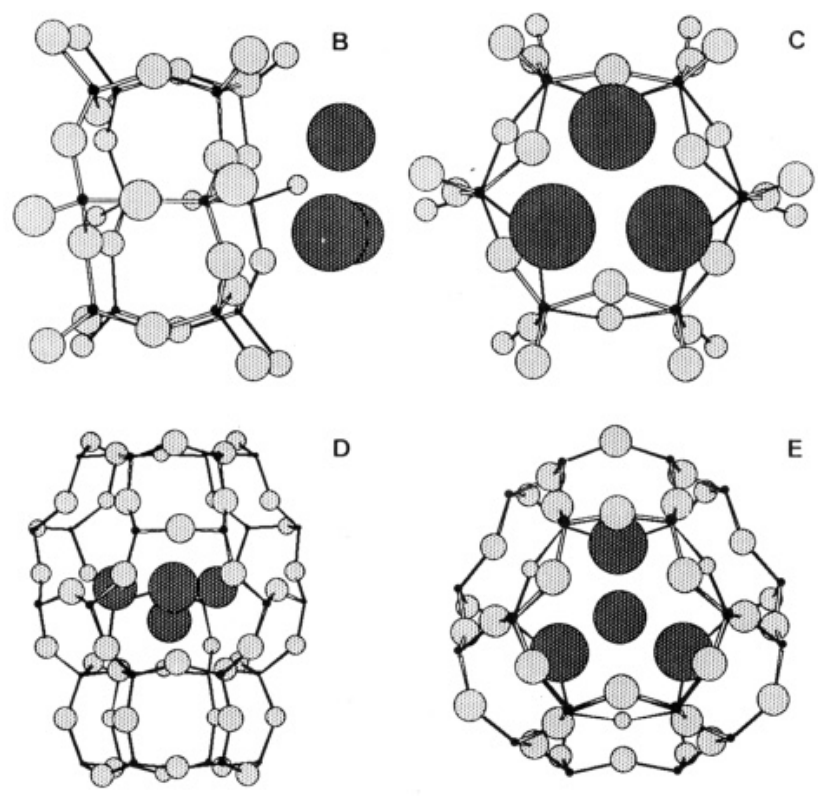

D

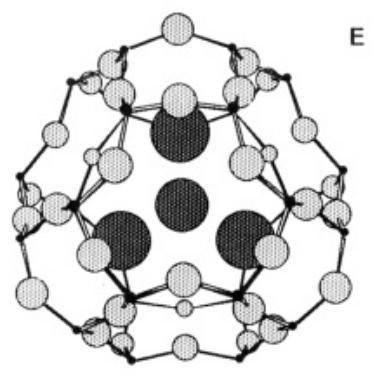

Figure 5. Geometric arrangements of palladium ensembles in a faujasite subunit. (A) Display of a partial faujasite unit cell with cation positions SI, SI', SII, and $\mathrm{SII}^{\prime}$. (B, C) Geometric arrangements of a palladium trimer located in front to a double six-ring (side and top view; Pd atoms dark shaded). (D, E) Four Pd atoms located in adjacent SI' $^{\prime}$ and SII $^{\prime}$ windows in a sodalite cage. Radii of atoms are sized as follows: $\mathrm{Si}^{4+}=$ $0.42 \AA ; \mathrm{O}^{2-}=1.32 \AA ; \mathrm{Pd}(0)=1.37 \AA . \mathrm{Si}^{4+}$ and $\mathrm{O}^{2-}$ atoms are shown with $30 \%$ of their ionic radii, and $\operatorname{Pd}(0)$ is shown with $60 \%$ of its metallic radius.

that on average each Pd atom is surrounded by three oxygens and six $\mathrm{Si} / \mathrm{Al}$ atoms. Four different sites in the zeolite framework would fulfil these requirements. They are indicated in Figure 5A, showing a $\mathrm{Si} / \mathrm{Al}$ skeleton of zeolite $\mathrm{X} / \mathrm{Y}$ : Truncated octahedra or sodalite cages are connected via $\mathrm{Si} / \mathrm{Al}$ six-rings to form the large supercage with a diameter of $12 \AA$. Four well-established cation positions are located between two $\mathrm{Si} / \mathrm{Al}$ six-rings (SI), slightly out of plane reaching into the sodalite unit (site $\mathrm{SI}^{\prime}$ ), in plane of a six-ring window to the supercage (SII) or out of plane into the sodalite unit $\left(\mathrm{SII}^{\prime}\right)$. Six bridging oxygens (omitted) alternate bending into or out of these windows and form the 3-fold coordination sites. A location of the palladium clusters in SI positions can clearly be ruled out. Only monovalent, small cations are known to have a distance of maximal $2.68 \AA$ to the lattice oxygens of this site. The $\mathrm{M}-\mathrm{O}$ bond length decreases further upon introducing higher valent cations into these sites due to distortion of the oxygen bridges. Zerovalent atoms or even clusters cannot be accommodated. Additionally, this position would require 6 oxygen and $12 \mathrm{Si} / \mathrm{Al}$ atoms to be detected for each palladium atom, far more than actually found.

Several quantitative geometric model calculations have been carried out in order to evaluate other arrangements of the palladium clusters close to zeolite six-ring windows. Two corresponding substructures are displayed in Figure 5. The pictures represent a zeolite double six-ring and sodalite unit in relation to palladium cluster arrangements. Input values for the zeolite structure were obtained from X-ray diffraction results. The Chem3D software allows placing atoms in relation to the zeolite subunits and gives accurate bond distances and angles between any desired atom pair. For example, a triangular palladium cluster 
with a Pd-Pd bond distance of $2.77 \AA$ was placed in front of the three oxygens of a sodalite double six-ring (Figure 5B,C). Orientations of this trimer staggered or on top of the three closest oxygen atoms, or pointed with only one Pd edge into the six-ring, gave in every case rise to more than one distance for each Pd atom to its oxygen or $\mathrm{Si} / \mathrm{Al}$ neighbors. The resulting spread in $\mathrm{Pd}-\mathrm{O}$ (e.g., in models $\mathrm{B}$ and $\mathrm{C}$ in Figure $5,2.2-4.4 \AA$ ) and $\mathrm{Pd}-\mathrm{Si}$ $(2.9-5.0 \AA)$ distances is so large that no distinctive $\mathrm{Pd}-\mathrm{O}$ or $\mathrm{Pd}-\mathrm{Si}$ contributions could be expected in the EXAFS analysis (each Pd would have several different oxygen neighbors). The arrangement of Pd dimers with one $\mathrm{Pd}$ atom on each side of a hexagonal window results in distances such as $\mathrm{Pd}-\mathrm{O}=2.6 \AA$ and $\mathrm{Pd}-\mathrm{Si} / \mathrm{Al}=3.43$ $\AA$ for each participating oxygen and silicon atom, close to the observed EXAFS results. However, the Pd-Pd coordination number is then only 1.0 instead of $1.5-1.9$.

Another alternative structure accommodates the experimental results very well. An arrangement of four palladium atoms occupying the sodalite unit as shown in Figure 5D,E corresponds to an average $\mathrm{Pd}-\mathrm{Pd}$ coordination number of $N=1.5$. Each palladium atom is located in front of one hexagonal window in dislocated $\mathrm{SI}^{\prime}$ or $\mathrm{SII}^{\prime}$ positions within the sodalite unit ( $\mathrm{SI}^{\prime *}$ and $\mathrm{SII}^{*}$ ). The $\mathrm{SI}^{\prime}$ sodalite position is surrounded by three nearest $\mathrm{SII}^{\prime}$ positions and vice versa. Every Pd atom can now encounter identical bond distances to all three oxygens as well as one bond distance to all $\mathrm{Si} / \mathrm{Al}$ atoms. If the bond length between crystallographically nonequivalent $\mathrm{Pd}$ neighbors $\left(\mathrm{SI}^{\prime}-\mathrm{SII}^{\prime}\right)$ of the $\mathrm{Pd}_{4}$ ensemble is set to $2.78 \AA$ and the metal atoms are positioned to have identical distances to the oxygen atoms in the six-rings, then the metal atoms in equivalent positions ( $\left.\mathrm{SI}^{\prime}-\mathrm{SI}^{\prime}, \mathrm{SII}^{\prime}-\mathrm{SII}^{\prime}\right)$ are over $4 \AA$ apart from each other. It follows that one palladium atom in $\mathrm{SI}^{\prime}$ position would encounter three Pd atoms in $\mathrm{SII}^{\prime}$ at $2.78 \AA$, but all three Pd atoms in SII' would detect only one palladium neighbor at this distance, resulting in an average coordination number $N$ of 1.5 as found in the fit. In addition, each of the three metal atoms in SII' should have a bond length of 4.1 $\AA$ to the two Pd atoms in equivalent $\mathrm{SII}^{\prime}$ coordination sites. However, even taking into account the $1 / r^{2}$ dependence of the magnitude in the Fourier transformation, the very small outer-shell scattering visible in the $4-\AA$ range of the EXAFS data suggests that not all of the palladium atoms are arranged in these $\mathrm{Pd}_{4}$ clusters. We assume therefore that the zeolites contain additional smaller species such as $\operatorname{Pd}_{2}(N=1.0)$ or $\mathrm{Pd}_{3}(N=1.33)$.

The $\mathrm{Pd}-\mathrm{Si} / \mathrm{Al}$ distance of $3.44 \AA$ found in the EXAFS fit agrees very well with $3.40 \AA$ obtained from the model calculations under the conditions described above for the model in Figure 5D,E. For $\mathrm{Pd}-\mathrm{O}$, a bond length of $2.65 \AA$ results from the model that is based upon structural data of $\mathrm{NaX}$ zeolite. The deviation of $0.11 \AA$ to the $2.76 \AA$ found from the EXAFS analysis has to be attributed to the flexibility of the $\mathrm{O}-\mathrm{Si}-\mathrm{O}$ angles in the framework, which are expected to change with differently coordinated species and/or upon reduction of the $\mathrm{Pd}$.

Our proposed model of $\mathrm{Pd}_{2}$ to $\mathrm{Pd}_{4}$ molecular clusters is comparable to the suggested structure for silver clusters in sodalite units, where the participating $\mathrm{Ag}$ atoms were located in $\mathrm{SI}^{\prime *}$ and $\mathrm{SII}^{\prime *}$ positions. ${ }^{17}$ Furthermore, X-ray diffraction studies of $\mathrm{Ca}$ (II)-exchanged and dehydrated zeolite $\mathrm{Y}$ and of $\mathrm{Cd}(\mathrm{II})$-exchanged zeolites $\mathrm{X}$ were interpreted with very similar arrangements in $\mathrm{SI}^{\prime *}$ positions, which are stabilized by $\mathrm{OH}$ or $\mathrm{H}_{2} \mathrm{O}$ in $\mathrm{SII}^{\prime}$ positions. ${ }^{34,35}$

We note that the molecular palladium clusters are also stable at $425 \mathrm{~K}$. In sample $\mathrm{PdX} 2$ the coordination number for $\mathrm{Pd}$ is slightly increased, probably indicating a higher population of the

(34) Costenoble, M. L.; Mortier, W. J.; Uytterhoeven, J. B. J. Chem. Soc., Faraday Trans. 1 1978, 74, 466.

(35) Calligaris, M.; Nardin, G.; Randaccio, L.; Zangrando, E. Zeolites 1986, 6,439 . proposed $\mathrm{Pd}_{4}$ clusters in the sodalite unit. The outer-shell scattering at about $4 \AA$ is increased with respect to sample $\mathrm{PdX}$ and gives further evidence for this interpretation. Additional oxygen neighbors are found in this sample with a shorter bond length of $2.28 \AA$, believed to be due to $\mathrm{OH}$ or $\mathrm{H}_{2} \mathrm{O}$ ligands. Similar bond distances have been found in cubelike $\mathrm{Cd}_{4}(\mathrm{O}, \mathrm{S})_{4}$ and $\mathrm{Cd}_{4}(\mathrm{O}, \mathrm{Se})_{4}$ clusters encapsulated in sodalite cages. ${ }^{36,37}$

The cluster geometry as described above explains the unusually long Pd-Pd distance exceeding the bulk value by $0.03 \AA$. Typically, bond contractions rather than elongations relative to the bulk values are reported for dimers in cold matrixes ${ }^{38}$ as well as for Pt or Pd clusters $>10 \AA$, and zeolite-supported $\mathrm{Pt} .{ }^{39,40} \mathrm{As}$ shown in EXAFS studies of supported Pd and Rh particles, a relaxation to the bulk metal-metal distance occurred when gases such as hydrogen or $\mathrm{CO}$ were adsorbed on the metal surface. ${ }^{41,42}$ On the other hand, increasing unit cell constants were reported upon incorporation of hydrogen into interstitial sites of $\mathrm{Pd}$ metal. ${ }^{43}$ The samples discussed here clearly contain no bulklike Pd particles; thus, a hydride phase cannot be responsible for the observed increased bond length. Molecular adsorption of $\mathrm{H}_{2}$ on the intrazeolite Pd clusters may not be ruled out. Matrix isolation experiments of $\operatorname{Pd}\left(\mathrm{H}_{2}\right)$ systems were interpreted by the formation of single- and double-bonded molecular hydrogen complexes. ${ }^{44}$ However, $\mathrm{H}_{2}$ adsorption is not necessary to explain the long $\mathrm{Pd}-\mathrm{Pd}$ bond distances. The Pd-Pd distance is clearly consistent with a partial occupation of dislocated sodalite six-ring positions.

The intrazeolite Pd clusters can be compared to triangular ligated molecular clusters such as $\mathrm{Pd}_{3}\left(\mathrm{SO}_{2}\right)_{2} \mathrm{~L}_{5}, \mathrm{~L}=t$-BuNC. The bridged and unbridged Pd-Pd distances ( 2.73 and $2.76 \AA$ ) are close to our results. ${ }^{45}$ Apparently the zeolite lattice serves as a stabilizing framework in a similar fashion as the ligands in the organometallic compound.

In conclusion, the intrazeolite stabilization of unusually small Pd clusters is possible through the interplay of two types of interaction: (1) The zeolite sodalite cage offers a stabilizing oxygen-coordination sphere for the reduced Pd atoms. (2) In addition, the different sets of $\mathrm{SI}^{\prime *}$ and $\mathrm{SII}^{\prime *}$ cage positions provide templates for the arrangement of palladium ensembles with sufficient $\mathbf{P d}-\mathbf{P d}$ bonding overlap. The well-defined "molecular clusters" with low nuclearity stabilized at ambient temperature in an open pore structure reported here are ideal model systems not only to study changes in electronic, optical, and vibrational characteristics but also to investigate their chemistry and catalytic properties under reaction conditions.

Acknowledgment. Acknowledgment is made to the donors of the Petroleum Research Fund, administered by the American Chemical Society, and to the Sandia University Research Program (DOE), T.B. We acknowledge valuable discussions with Professor D. E. Sayers. The operational funds for NSLS beam line X11A are supported by DOE Grant DE-ASO580ER 10742.

(36) Herron, N.; Wang, Y.; Eddy, M. M.; Stucky, G. D.; Cox, D. E.; Moller, K.; Bein, T. J. Am. Chem. Soc. 1989, 111, 530

(37) Moller, K.; Eddy, M. M.; Stucky, G. D.; Herron, N.; Bein, T. J. Am. Chem. Soc. 1989, 111, 2564.

(38) Moskovits, M. In Metal Clusters; Moskovits, M., Ed; Wiley: New York, 1986; p 185.

(39) Moraweck, B.; Clugnet, G.; Renouprez, A. Surf. Sci. 1979, 81, L631

(40) Moraweck, B.; Renouprez, A. Surf. Sci. 1981, 106, 35.

(41) Morawek, B.; Clugnet, G.; Renouprez, A. J. Chim. Phys. 1986, 83, 265 .

(42) Van't Blik, H. F. J.; Van Zon, J. B. A. D.; Koningsberger, D. C.; Prins, R. J. Mol. Catal. 1984, 25, 379.

(43) Lewis, F. A. The Palladium Hydrogen System; Academic Press: London, 1967

(44) Ozin, G. A.; Garcia-Prieto, J. J. Am. Chem. Soc. 1986, 108, 3099

(45) Otsuka, S.; Tatsuno, Y.; Miki, M.; Aoki, T.; Matsumoto, M.; Yoshioka, H.; Nakatsu, K. J. Chem. Soc., Chem. Commun. 1973, 445. 